Thorax (1955), 10, 253.

\title{
BENIGN HISTOPLASMOSIS
}

\author{
BY \\ RICHARD LEIGH AND HAROLD E. THOMAS \\ From West Heath Hospital and the Birmingham Chest Clinic
}

(RECEIVED FOR PUBLICATION DECEMBER 28, 1954)

Histoplasmosis is an infection caused by the fungus Histoplasma capsulatum. This infection may be generalized, in which case it is usually fatal, or localized to the lungs, when survival and eventual calcification of the lesions generally result. Focal lesions are also found. The disease, which occurs chiefly in the North American continent, has been reported 10 times in the United Kingdom. An eleventh case, which was probably contracted in the United States of America, is reported below.

Knowledge of histoplasmosis has accrued from investigations of acute cases and research into the aetiology of unusual pulmonary lesions.

Opie and McPhedran (1926) found an appreciable number of children with pulmonary radiographic shadows, previously interpreted as tuberculous, who did not react to $1 \mathrm{mg}$. of tuberculin, and this observation was repeated by many other American workers (Barnard, Amberson, and Loew, 1931 ; Nelson, Mitchell, and Brown, 1938 ; Crimm and Short, 1939 ; Gass, Murphy, Harrison, Puffer, and Williams, 1941 ; Gass, Harrison, Puffer, Stewart, and Williams, 1943). In reviewing the chest radiographs of 53,400 men on induction to the American Forces, Long and Stearns (1943) found that both multiple and miliary calcifications were more frequent and more extensive in men from the Middle West than in men from the rest of the country.

Zarafonetis and Lindberg (1941) prepared histoplasmin, and surveys of histoplasmin sensitivity were made. Palmer (1945) and Christie and Peterson (1946) suggested that the association of the histoplasmin skin test with calcification is not fortuitous, but that it indicates an infection with $H$. capsulatum in the past. This was supported by similar investigations (Zwerling and Palmer, 1946 ; Palmer, 1946 ; High, Zwerling, and Furcolow, 1947 ; Dickie and Clark, 1948). Furcolow (1949) described the isolation of $\boldsymbol{H}$. capsulatum from soft lesions undergoing calcification in two patients with positive histoplasmin and negative tuberculin skin reactions.
Schulz (1950) found a calcifying pulmonary lesion containing $H$. capsulatum in an infant who died of generalized histoplasmosis.

\section{DISTRIBUTION}

The original three cases of disseminated histoplasmosis were described by Darling $(1906,1908$, 1909) from the Panama Canal zone. The first American case came from the State of Minnesota (Riley and Watson, 1926). Since then cases have been reported from the following countries: Anglo-Egyptian Sudan, Argentina, Australia, Austria, Brazil, Bulgaria, Colombia, French Sudan, Great Britain, Hawaii, Honduras, Java, Mexico, the Netherlands, Panama, Philippines, Portugal, South Africa, Spain, Turkey, and Uruguay.

The disease appears to be more prevalent in areas adjacent to streams and other areas of dampness than on high ridges. Beadenkopf and Loosli (1951) suggest that $H$. capsulatum is disseminated in the Mississippi valley by floods carrying a soilfungus mixture which is later air-borne. In Brazil and Argentina the greatest prevalence is in similar areas.

Attempts have been made to plot the distribution of the infection by histoplasmin skin testing. The highest incidence appears to be in America in an area limited by the Arkansas and the Mississippi rivers on the west, the Great Lakes to the north, the Appalachians to the east, and the Gulf of Mexico to the south, involving especially the States of Illinois, Tennessee, Arkansas, Missouri, Ohio, and Mississippi. In Canada, only the south-eastern provinces have yielded significant positive results (Guy, Roy, Poupart, and Panisset, 1949 ; Guy, Panisset, and Frappier, 1949). High sensitivity has been found in some areas of Mexico, Central America, and South America. Scanty surveys done in Asia have shown few reactions to histoplasmin. Little is known from the continent of Africa, but it seems that the prevalence rate in South Africa is low. 
The various surveys carried out in Europe have shown virtually no sensitivity to histoplasmin. Most of the rare cases reported in Europe have been in patients who have previously resided in endemic areas.

In England a fatal case of histoplasmosis in a British soldier who had served in France, India, and the Sudan was described by Derry, Card, and Wilson (1942). Duncan (1947) reported a case with dermal lesions. Limerick (1951) mentions a case in which $H$. capsulatum was isolated from a post-appendicectomy abscess in a patient who had never been out of England. Hutchison (1952) describes a case of laryngeal histoplasmosis resembling carcinoma ; the source of infection was considered to be in the Far East, which the patient had visited. Two further cases of acute disseminated histoplasmosis have been reported in England by Locket, Atkinson, Grieve, and Bridson (1953) and Poles and Lavertine (1954). Both these patients had been abroad. Cases of pulmonary calcification with positive histoplasmin skin tests have been described in England by Arblaster (1950), Crofton (1950, two cases), and Sakula (1953). All these patients had visited the North American continent. Two further personal cases are mentioned by Symmers (1953).

\section{CASE RePORT}

M. M., a 42-year-old Jamaican, was first seen in October, 1952, on account of cough of two and a half months' duration. He had lived in Jamaica until June, 1944, when he went to Springfield, Ohio, U.S.A., to work on a dairy farm, remaining there until December, 1947. He was never ill except for one occasion when he had a cold associated with a cough. A radiograph of the chest in March, 1947, was said to be "negative for tuberculosis." Between December, 1947, and December, 1949, he spent periods of about six months in New Jersey, Florida, New York State, and Florida again ; in December, 1949, he returned to Jamaica.

In October, 1951, he came to England and was well until June, 1952, when he developed a cough with about $1 \mathrm{oz}$. of clear sputum daily; there were no other symptoms and he did not feel ill. In October no clinical abnormality was found except for a left inguinal hernia. Radiologically small scattered foci of calcification suggestive of pulmonary histoplasmosis were seen in both lung fields.

In November, 1952, he was admitted to hospital for surgical relief of his hernia ; this was followed by a period of convalescence, after which he returned to his work as a storekeeper in January, 1953. On January 6, 1953, he was seen again and an intradermal histoplasmin test was done, using $0.1 \mathrm{ml}$. of $1 / 100$ solution. Seventy-two hours later there was erythema with induration $12 \mathrm{~mm}$. in diameter, but no vesication.

On January 26, 1953, he felt unwell. His cough increased, and he developed pain in the right lower chest. His sputum became pink, and increased to 3-4 oz. (90-120 ml.) per day. Four days later a diagnosis of right middle lobe pneumonia was made, and he was admitted to hospital. Culture of sputum gave a predominant growth of Strep. viridans and a few colonies of Strep. pneumoniae and $N$. catarrhalis.

He was treated with 3 million units of penicillin daily for three days followed by 2 million units daily for 14 days, and made a satisfactory clinical and radiological recovery. Bronchoscopy on February 28 showed normal appearances, the right middle lobe bronchus in particular being patent and clean. He was discharged from hospital on March 4. In view of the lung calcifications and the positive histoplasmin intradermal test, further investigations were undertaken. Skin tests were repeated, and serial complement-fixation and collodion particle agglutination tests were performed; the results of these are shown in Table I.

TABLE I

RESULTS OF SKIN TESTS AND OF SERIAL COMPLEMENT. FIXATION AND COLLODION PARTICLE AGGLUTINATION TESTS

\begin{tabular}{|c|c|c|c|}
\hline \multirow{2}{*}{ Date } & \multicolumn{3}{|c|}{ Skin Test } \\
\hline & Histoplasmin & Coccidioidin & Tuberculin \\
\hline $\begin{array}{l}\text { April, } 1945 \\
\text { March, 1947 } \\
\text { Jan., 1953 } \\
\text { Feb., 1953 } \\
\text { May, } 1953\end{array}$ & + ve $(1: 100)$ & $-v e(1: 100)$ & $\begin{array}{l}\text { Negative (patch test) } \\
\text { Positive " " } \\
\text { Positive }(1: 1,000)\end{array}$ \\
\hline
\end{tabular}

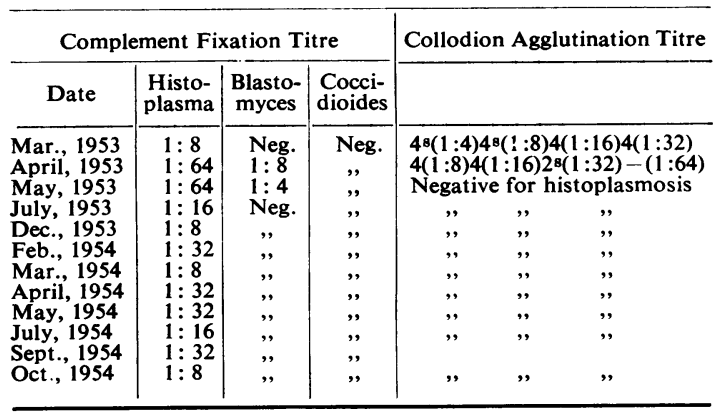

In February, 1953, the fungus could not be recovered from the sputum or blood. The sternal marrow was not investigated.

\begin{tabular}{c|c|c}
\hline Date & Hb (g.) & W.B.C. \\
\cline { 1 - 3 } $31 / 1 / 53$ & 15.6 & $11,400(\mathrm{P} 67 \%, \mathrm{~L} 21 \%, \mathrm{M} 12 \%)$ \\
$3 / 3 / 53$ & 15.0 & $8,900(\mathrm{P} 5 \%, \mathrm{E} 6 \%, \mathrm{~L} 26 \%, \mathrm{M} \% \%, \mathrm{~B} 1 \%)$ \\
$8 / 4 / 53$ & 16.4 & $8,200(\mathrm{P} 5 \%$ \\
\hline
\end{tabular}


The radiological appearances of the lungs in December, 1954 (Fig 1), do not differ from those in October, 1952. The patient remains well, and is now working as a storekeeper.

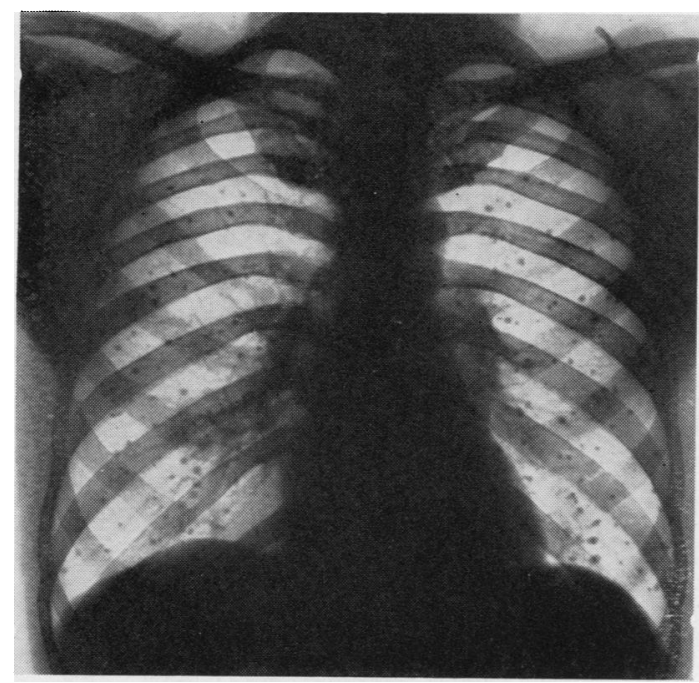

Fig. 1

\section{Discussion}

Clinical Features of Benign Histoplasmosis. - The clinical features of the acute phase of the benign disease can be gleaned from accounts of the earlier epidemics and from the description of laboratory infections (Furcolow, Guntheroth, and Willis, 1952). The incubation period is from five to 21 days. The symptoms are of fever, tachycardia, sweating, vague burning chest pains, headache, weakness, cough, sputum, and loss of weight. The findings include rales, splenomegaly, and hepatomegaly, but there may be few physical findings. The final calcified phase of the benign disease is usually an unexpected finding in a patient who has a chest radiograph for another purpose. Cough and sputum have been usual symptoms. Severe haemoptysis has been reported (Arblaster, 1950).

Appearances of Chest Radiographs.-The radiographic appearances in pulmonary histoplasmosis fall into two groups, depending on the presence or absence of calcification.

Without Calcification.-In this group the lesions may be of four main types. They may show (Furcolow, 1949 ; Holt, 1947 ; Sontag and Allen, 1947) (1) miliary lesions with uniform fine granular deposits throughout both lung fields; (2) fluffy, mottled, or strand-like shadows which may be either single or multiple ; (3) a few unevenly distributed nodular foci or multiple large conglomerate patchy areas often $2.5 \mathrm{~cm}$. or more in diameter ; (4) pneumonic infiltrations of a granular patchy type or an unresolved pneumonia.

Cavitation may also be present (Bunnell and Furcolow, 1948 ; Bettag, 1951 ; Hodgson, Weed, and Clagett, 1951; Jackson, 1952; Peeples and Spence, 1954). Enlargement of the hilar glands may be associated with any of the above types of lesion, and Furcolow (1949) states that this is seen in half the cases.

With Calcification.-Calcification begins to show 12 to 15 months after the initial lesions have developed and is marked in two or three years. In hilar lymph nodes it often does not occur until two and a half or more years later (Sontag and Allen, 1947). It appears to occur earlier in children and has been noted in a child aged 10 months (Christie and Peterson, 1945).

The general appearances are of two main types:

(1) Miliary calcification is seen as numerous uniform small round lesions $2-3 \mathrm{~mm}$. in diameter, widely and symmetrically disseminated in the lung fields (High and others, 1947; White and Hill, 1950). (2) Scattered bilateral multiple calcifications are seen as deposits, irregular in outline, often asymmetrical and varying in size up to 2.5 $\mathrm{cm}$. in diameter. A "dot and ring" or "halo" type of calcification is described (Furcolow, Mantz, and Lewis, 1947); these appearances are not limited to histoplasmosis but may be seen in pulmonary haemangioma and tuberculosis.

Calcification also develops in the hilar lymph nodes: this may be present in association with either of the above radiographic types. The nodes or the conglomerate masses may calcify as smaller units which coalesce to give a raspberry-like appearance.

Differential Diagnosis of Radiographic Shadows. -In general there is no striking or distinguishing feature. The asymptomatic forms resemble pulmonary tuberculosis in all stages and are frequently confused with it. Beadenkopf and Loosli (1951) state that there is a tendency among histoplasmin reactors to have a nodular type of infiltrate located in any area of the lung field in contrast to tuberculin reactors, who have softer infiltrates located towards the apices. Holt (1947) concludes that histoplasmosis belongs to that relatively large group of pulmonary disease in which the radiologist must be content to identify the presence of an abnormality and to offer suggestions without arriving at an exact diagnosis. 
Clinical Tests.-Histoplasmin sensitivity has been investigated since Zarafonetis and Lindberg (1941) prepared histoplasmin. The test is performed in the same way as the tuberculin reaction, $0.1 \mathrm{ml}$. of antigen being injected intradermally; a positive response is shown by an area of erythema and oedema $10 \mathrm{~mm}$. or more in diameter. A 1 in 100 solution of histoplasmin is used, although some investigators have used a 1 in 1,000 solution. Cross-reactions are known to occur with other fungus infections. Thus Emmons, Olson, and Eldridge (1945) showed in experimentally infected guinea-pigs that animals infected with histoplasma reacted to histoplasmin, blastomycin, coccidioidin, and haplosporangin. It is known that crossreactions are particularly likely to occur between histoplasmin and blastomycin. However, it has been shown that the antigens are specific if used in high dilutions. In acute cases and old age the histoplasmin skin test may give a negative result.

Saslaw and Campbell $(1948,1949)$, having shown that sera from rabbits immunized with $H$. capsulatum agglutinated collodion particles sensitized with histoplasmin, found similar agglutination in the presence of serum obtained from patients in the acute phase of histoplasmosis. They found weak agglutination in low dilutions $(1: 5$ to $1: 20)$ in $30.4 \%$ of a group of 197 healthy volunteers, and strong agglutination in three patients in the acute phase of histoplasmosis. The sera of three ambulant patients known to have had the disease from two to five years gave no significant results, being essentially the same as those found in some normal volunteers. The results of collodion agglutination tests paralleled those observed with yeast-phase antigens in the complement fixation test. In later investigations Saslaw and Campbell (1950) noted that serological titres gradually dropped, showing the highest peak two to four weeks after infection, and that within five to eight months titres had dropped to "baseline levels." However, Campbell (1954) states that in some cases titres persist at fairly high levels for a period of two or three years even when clinical recovery appears to be complete. Salvin, Weber, Lackman, Nishio, and Menges (1954) consider that high titres can persist for four to five years.

A fall in the titre was also observed by Grayston (1952) doing serial studies in a family with acute histoplasmosis. He performed the complement fixation test on the sera of 2,000 persons ; only seven reactions at a dilution of greater than 1:40 were found, five being in cases of culturally proved histoplasmosis, and two were sons of a proved case. Two further positive cases reacted at a dilution of $1: 20$. Saslaw and Campbell (1949) suggest that a strong reaction in a dilution of $1: 40$ or greater is significant. Repeated weekly histoplasmin skin tests may result in "false positive" collodion agglutination reactions in skin-testpositive persons, but a single skin test does not cause any alteration in antibody response in the subsequent four weeks (Prior and Saslaw, 1952).

Just as with the histoplasmin skin test, so with serological tests there may be a cross-reaction with blastomycosis, so that concurrent testing with blastomyces antigen should be carried out. It also appears that in fulminating cases of histoplasmosis serological tests may be negative or titres may be very low.

Diagnosis.-The undisputed diagnosis in all types of cases depends on the detection of the fungus. This may be by culture from blood, sputum, gastric washings, faeces, and bone marrow. It can also be found by microscopy or by culture of biopsy material, e.g., lymph node, skin, larynx. This is often achieved in the acute and subacute types of disease. In a case of benign pulmonary calcification Johnson and MacCurdy (1952) succeeded in culturing the organism from a cervical lymph node.

In benign pulmonary calcification a presumptive diagnosis can be made on three factors: (1) The presence of pulmonary calcification of a miliary type or of bilateral multiple type with or without hilar glandular enlargement, (2) a history of residence in an endemic area, and (3) positive histoplasmin and negative coccidioidin skin reactions. Mochi and Edwards (1952) state that in an area where histoplasmosis is known to be present a definite reaction to histoplasmin is generally construed as evidence of infection with $\boldsymbol{H}$. capsulatum.

The complement-fixation and collodion-agglutination tests, if positive, suggest active disease.

\section{COMMENT}

Campbell and Binkley (1953) discuss fully the serological reactions in mycotic disease using collodion agglutination (CA) tests with histoplasmin and blastomycin as antigens, and complementfixation (CF) tests with coccidioidin and yeastphase antigen from $H$. capsulatum and Blastomyces dermatitidis. In the CA test they added the intensity of the reactions (expressed as a number) at each of the serum dilutions, and produced a figure known as the CA value. A value of 5 to 9 was considered equivocal, while values above 10 were regarded as a positive result. However, cross-reactions were so extensive with this test that these authors interpreted positive findings as presumptive evidence of a mycotic infection rather 
than as a specific test for histoplasmosis. In the $\mathrm{CF}$ test reactions with heterologous antigens occur, and the titre may be higher than the homologous one in cases where the fungus is isolated. However, sera from cases of histoplasmosis rarely cross-react with coccidioidin antigen, and if this does occur the heterologous titre is low.

Using histoplasmin as the sensitizing agent, CA values of 16 and 10 were obtained with serum from this patient. This evidence of a mycotic infection is supported by high CF titres for Histoplasma, with low or negative titres for Blastomyces and Coccidioides.

The required criteria for a presumptive diagnosis of benign pulmonary histoplasmosis are fulfilled. Support is given by the results of the serological tests. The results of these tests in 1953 might be construed as evidence of continued activity either in the lungs or in some extrapulmonary site. However, there has been no radiological evidence of active pulmonary histoplasmosis or of pulmonary reactivation, nor have we been able to demonstrate a lesion elsewhere. We therefore suggest that the high titres obtained early in 1953 were due to an anamnestic response following the pneumonia, and substantiate that the aetiological agent of the pulmonary calcification was the fungus $H$. capsulatum.

We think that greater use of these serological tests might be made to support the diagnosis of suspected fungus infections in cases where the organism is not isolated.

\section{SUMMARY}

A further case of benign histoplasmosis diagnosed in Britain is reported. An anamnestic response to the serological tests for fungi is noted.

The disease is described and the literature reviewed.

We are especially indebted to Miss Charlotte C. Campbell, of the Army Medical Service Graduate School, Washington, for the serological tests and for her continued advice in the investigation of this case.

We wish to acknowledge the help received from Dr. Sandiford and Dr. Congden, of the Public Health Laboratory, Birmingham, and to thank Dr. A. M. Nussey for his helpful suggestions in the preparation of this paper.
BIBLIOGRAPHY

Arblaster, P. G. (1950). Thorax, 5, 333.

Barnard, M. W., Amberson, J. B., Jr., and Loew, M. F. (1931) Amer. Rev. Tuberc., 23, 593.

Beadenkopf, W. G., and Loosli, C. G. (1951). J. Amer. med. Ass., 146, 621 .

Bettag, O. L. (1951). J. thorac. Surg., 22, 434.

Bunnell, I. L., and Furcolow, M. L. (1948). Publ. Hlth Rep., Wash. 63, 299.

Campbell, C. C. (1954). Personal communication.

- and Binkley, G. E. (1953), J. Lab. clin. Med., 42, 896

Christie, A., and Peterson, J. C. (1945). Amer. J. Publ. Hlth, 35, 1131 (1946). J. Amer. med. Ass., 131, 658.

Crimm, P. D., and Short, D. M. (1939). Amer. Rev. Tuberc., 39, 64

Crofton, J. (1950). Thorax, 5, 340.

Darling, S. T. (1906). J. Amer. med. Ass., 46, 1283.

- (1908). Arch. intern. Med., 2, 107.

- (1909). J. exp. Med., 11, 515.

Derry, D. C. L., Card, W. I., and Wilson, R. (1942). Lancet, 1, 224

Dickie, H. A and Clark E. A (1948). Ann. intern. Med., 28, 1087

Duncan, J. T. (1947). Trans. roy. Soc. trop. Med. Hyg., 40, 364.

Emmons, C. W., Olson, B. J., and Eldridge, W. W. (1945). Publ. Hlth Rep., Wash., 60, 1383.

Furcolow, M. L. (1949). Ibid., 64, 1363.

- Guntheroth, W. G., and Willis, M. J. (1952). J. Lab. clin. Med., 40, 182

Mantz, H. L., and Lewis, I. (1947). Publ. Hlth Rep., Wash., 62, 1711 .

Gass, R S. Harrison E. F. Puffer, R. R., Stewart, H. C., and Williams, W. C. (1943). Amer. Rev. Tuberc., 47, 379.

Murphy W. J., Harrison, E. F., Puffer, R. R., and Williams, Murphy, W. J., Harrison, E. F., Puffer,

Grayston, J. T. (1952). J. Lab. clin. Med., 40, 90.

Guy, R. Panisset, M., and Frappier, A. (1949). Canad. J. publ. Hlth, 40, 306.

Roy, O., Poupart, G., and Panisset, M. (1949). Ibid., 40, 68.

High, R. H., Zwerling, H. B., and Furcolow, M. L. (1947). Publ. Hlth Rep., Wash., 62, 20.

Hodgson, C. H., Weed, L. A., and Clagett, O. T. (1951). J. Amer. med. Ass., 145, 807.

Holt, J. F. (1947). Amer. J. Roentgenol., 58, 717.

Hutchison, H. E. (1952). J. Path. Bact., 64, 309.

Jackson, F. I. (1952). S. Afr. med. J., $26,460$.

Johnson, J. E., and MacCurdy, J. M. (1952). Amer. Rev. Tuberc., 66, 497.

Limerick, C. B. (1951). Brit. med. J., 1, 885.

Locket, S., Atkinson, E. A., Grieve, W. S. M., and Bridson, E. (1953). Ibid., 2, 857.

Long, E. R., and Stearns, W. H. (1943). Radiology, 41, 144

Mochi, Bull. Wld Hlth Org., 5, 259.

Mochi, A., and Edwards, P. Q. (1958). Amer. Rev. Tuberc., 37, 311 .

Opie, E. L., and McPhedran, F. M. (1926). Ibid., 14, 347.

Palmer, C. E. (1945). Publ. Hlth Rep., Wash., 60, 513. (1946). Ibid., 61, 475.

Peeples, W. J., and Spence, M. J. (1954). Amer. Rev. Tuberc., 69, 111.

Poles, F. C., and Lavertine, J. D. O'D. (1954). Thorax, 9, 233.

Prior, J. A., and Saslaw, S. (1952). Amer. Rev. Tuberc., 66, 588.

Riley, W. A., and Watson, C. J. (1926). Amer. J. trop. Med., 6, 271.

Sakula, A. (1953). Tubercle, Lond., 34, 18.

Salvin, S. B., Weber, R. W., Lackman, D. B., Nishio, J., and Menges, G. (1954). J. Lab. clin. Med., 44, 56.

Saslaw, S. and Campbell, C. C. (1948). Proc. Soc. exp. Biol., N.Y., 68, 559 .

(1949). Publ. Hlth Rep., Wash., 64, 424.

(1950). Amer. J. publ. Hlth, 40, 427.

Schulz, D. M. (1950). Arch. Path., Chicago, 50, 457.

Sontag, L. W and Allen, J. E. (1947). J. Pediat., 30, 657.

Sontag, L. W., and Allen, J. E. (1947), J. Pedia

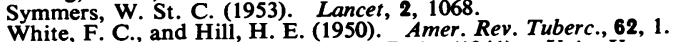

Zarafonetis, C. J. D., and Lindberg, R. B. (1941). Univ. Hosp. Bull. Ann Arbor, $7,47$.

Zwerling, H. B., and Palmer, C. E. (1946). Radiology, 47, 59 